\title{
Identifying skeletal remains with the help of dental data provided by the family in the absence of proper ante mortem dental records: Case report
}

Samarasekare $A^{1}$, Wijeratne $N A S P^{1}$, Ranasinghe $S^{1}$

Institute of Legal Medicine and Toxicology, Colombo

*Corresponding author: Tel: 0094-71444289. E-mail address: ranasinghe sk@yahoo.com

MLJSL. Vol 1. No 2. Aug. pp 51 - 55

\begin{abstract}
:
Human skeletal remains were received from the office of the Judicial Medical Officer (JMO), Teaching Hospital (TH) Jaffna for the establishment of identification of the deceased. After thorough evaluation of the dentition (Oral autopsy), the author found several unique features which would invariably help to identify the deceased if ante-mortem (AM) data were available. On the request of the MO-Medico Legal, TH Jaffna provided a written document which detailed about AM dental data of a missing 22 year old female collected from the parents. The data thus provided exactly matched with postmortem (PM) findings of dentition and hence the probable identification was established. This case report highlights the mode of AM data collected, the manner of data interpretation and the importance of AM data collection using a checklist by forensic investigators and police officers who handle such cases in order to improve the process.
\end{abstract}

Key words: skeletal remains, identification, oral autopsy, dental records

\section{Introduction:}

Identification of an unknown body or skeletal remains for forensic purposes is a multidisciplinary process. Identification following oral autopsy involves processing of AM dental data and comparison with the PM information, in order to reach an expert opinion about the deceased. [1]

The unique structures and traits of human teeth and jaws readily lend themselves to use in the identification of living and deceased victims. Dental data can be recovered and recorded at the time of postmortem examination and compared to ante-mortem data that are supplied by general and/or specialist dentists who treated the victim during their lifetime. This is especially true of treatments in the teeth, such as restorative and aesthetic fillings and crowns, root canal procedures and dentures since these are custom-made as unique treatments for each individual [2]. Furthermore AM dental data such as dental charts with clinical notes, radiographs, dental casts, tooth 
anomalies etc. obtained from the dental practitioner are also important.

In other countries where forensic odontology is successfully used for routine cases, the law enforcing agencies collect necessary AM data from the dental practitioner/s who treated any missing person [3].But in developing countries where properly maintained comprehensive dental records are not available forensic odontology practitioners have limited opportunity in achieving positive identification by dental means per se.

Therefore until the standards of general dental practice improve to support this discipline of dentistry, investigators should follow an alternative mechanism to obtain AM dental data. This case report highlights the value of AM dental data collected from a missing person when properly maintained dental data are not accessible.

\section{Case report:}

A body bag containing unknown skeletal remains referred by the MO-Medico Legal, TH, Jaffna was submitted to the Forensic Odontology Unit, Institute of Legal Medicine and Toxicology (ILMT) Colombo through the chief JMO on $09^{\text {th }}$ February 2010 (Fig. 1). The skeletal remains were subjected to oral autopsy and radiological investigation of the whole mandible.

The examination revealed that the bones were relatively heavy, wet, foul smelling and free from soft tissue remnants. There were thirteen teeth collected from the remains and they were repositioned into the corresponding sockets of the arches based on dental morphology [4].
Figure: 1 skeletal remains in the body bag

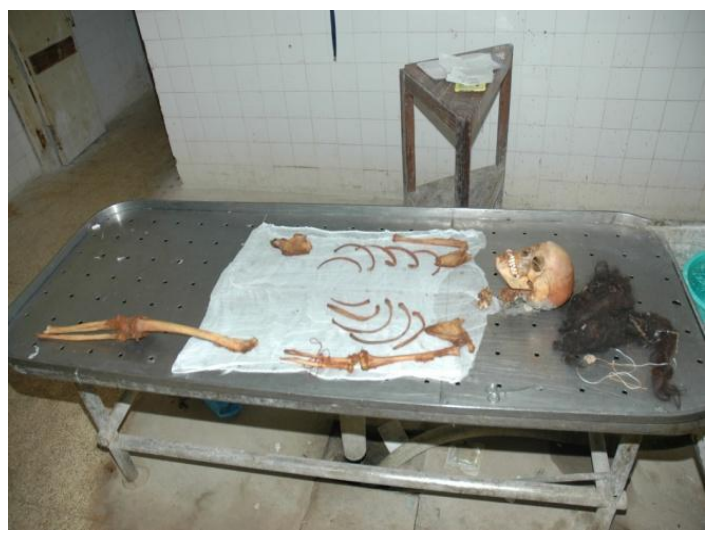

The left and right central incisor teeth were not found leaving open sockets at their position in the maxilla and therefore noted as "postmortem missing". There was an additional open tooth socket which was relatively smaller in diameter at the midline of the pre-maxilla, just behind two sockets for the central incisors (shown with an arrow in Fig. 2). On the palate the palatine suture was not yet fused.

The mandible appeared to be that of a young person and had only five teeth. All anterior teeth (central incisors, lateral incisors and canines) and two first premolars (both left and right) were missing due to postmortem changes where the sockets were left open. On left side of the mandible the $1^{\text {st }}$ molar was missing and $2^{\text {nd }}$ molar had occupied the space for the $1^{\text {st }}$ molar. The $2^{\text {nd }}$ premolar had tilted backwards (towards the $1^{\text {st }}$ molar) and the $3^{\text {rd }}$ molar had drifted mesially and inclined towards the $2^{\text {nd }}$ molar.

On the right side of the mandible, $1^{\text {st }}$ molar was missing and the socket had healed well. The $2^{\text {nd }}$ molar was missing 
after death. The $2^{\text {nd }}$ premolar had tilted backwards. (Fig. 3)

The colour of the teeth appeared chalky to some extent. Those premolar and molar teeth in the maxilla were subject to minimal attrition on their occlusal surfaces.

\section{Figure 2: Maxillary bones with teeth}

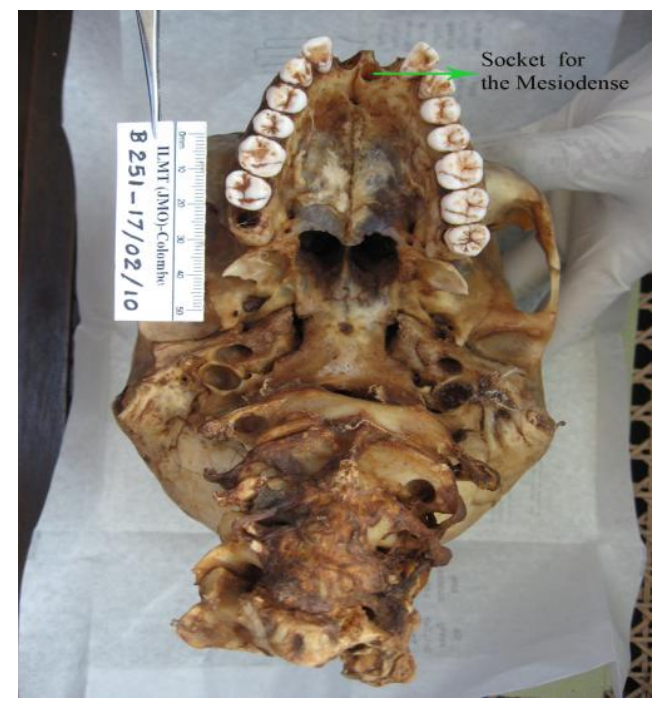

The AM data was provided by the MOMedico-Legal, TH Jaffna as a type written document for comparison with PM data following requests made by the authors and the AM data had been collected from the parents of a 22 year old missing female (born in 1988). According to their vague memory, there had been a sharp small tooth behind the upper front teeth at the midline and two dental extractions had been done in the lower jaw before 1995 and in between 1996 and 2000. There was a photograph of the victim in smiling posture annexed with the document provided by the MO Medico-legal, TH Jaffna.

\section{Discussion:}

Even though dental identification is a cost beneficial and less time consuming procedure the positive identification by dental means has not been highly successful in our country due to the prevailing situation at the dental health care delivery points.

\section{Figure 3: Mandible and teeth}

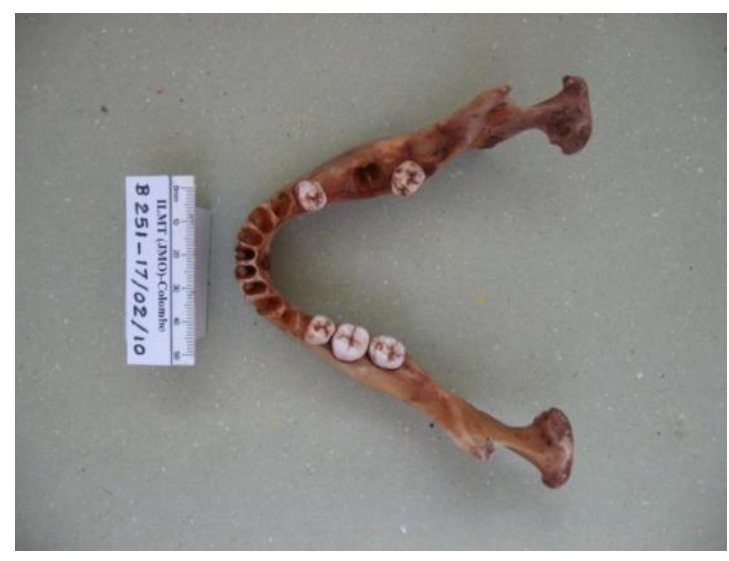

Since the dental identification is done purely on the comparison of PM data with AM dental records, lack of maintaining AM data by dental professionals is the main drawback in this task. In order to overcome this deficit, some AM data could be obtained from the relatives and close friends who claim the body.

In this particular case the small socket observed at the oral autopsy was for a "Mesiodense" which are defined as supernumerary teeth present in the midline of the maxilla between the two central incisors(5). They are the most common supernumerary teeth but the prevalence in Sri Lanka is not known. According to the AM information the small sharp tooth described by the parents should be a Mesiodense and the socket was compatible with a Mesiodense as shown in Fig 2. 
As far as the dental extractions which were done at two different intervals are concerned if the $1^{\text {st }}$ molar was extracted well before 1995, the age of the victim should have been below 7 years. As the $1^{\text {st }}$ molar erupts at the age of 6 years and if the $1^{\text {st }}$ molar was removed early at the age of 6 to 7 years just after eruption due to dental caries or any other reason, the $2^{\text {nd }}$ molar could occupy that space(socket), the $2^{\text {nd }}$ premolar could tilt backwards and $3^{\text {rd }}$ molar could drift mesially due to natural forces. The left side of the mandible shows all these changes in Fig. 3 and the radiograph of the mandible shown in Fig. 4 clearly shows these effects.

The $1^{\text {st }}$ molar on the right side should have been extracted at the age of 11 to 15 years according to the AM data. The $2^{\text {nd }}$ molar erupts at the age of 12 years and hence there was no possibility for the $2^{\text {nd }}$ molar to occupy the socket for the $1^{\text {st }}$ molar as occurred in the left side of the mandible. The radiograph of the mandible right side (Fig. 5) shows that the socket after the extraction of $1^{\text {st }}$ molar had healed well with slight distal inclination of $2^{\text {nd }}$ premolar [6].

The colour of the teeth being chalky in appearance indicates the deposition of minerals (Mild Fluorosis) in that geographical area. The colour of the teeth was also compatible with that in the photograph of suspected missing girl.

The age was estimated based on $3^{\text {rd }}$ molar development in this case. Accordingly the estimated age falls between 21 to 25 years with an average of 23 years at the time of death, based on the methods established for age estimation using radiographs of tooth development $[7,8,9,10 \& 11]$.
Figure 4: Radiograph of the left mandible

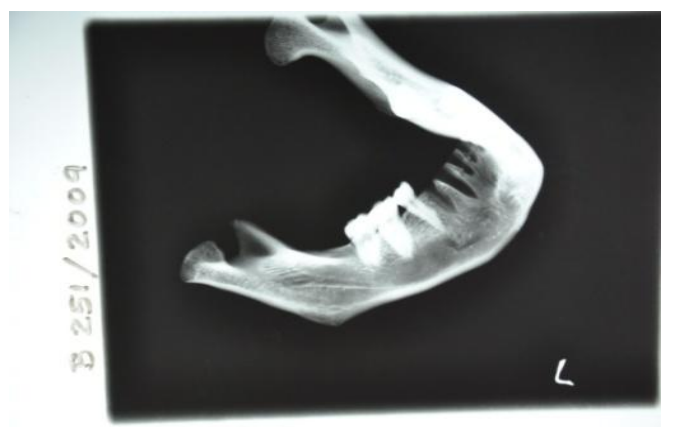

Figure 5: Radiograph of the right mandible

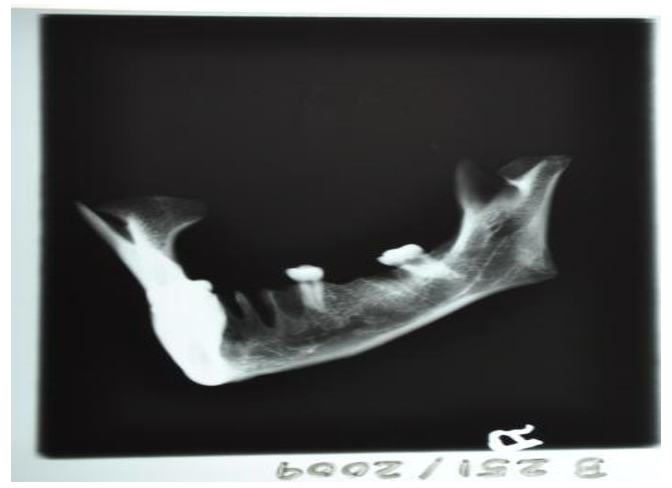

\section{Conclusion:}

Probable identification was established with very high certainty since the PM dental data of skeletal remains examined were compatible with the AM information provided by the MO-Medico Legal, TH Jaffna. The specific feature of Mesiodense, two ordinary dental extractions done at two different ages during the childhood and the dental age estimated by the author concluded the probable identity of the missing girl who was suspected to be the daughter of parents who gave AM information. The characteristics that were compatible in this case during the comparison of PM and $A M$ data were minimal for positive 
identification to be met ( INTERPOL 2009 16) and therefore DNA profiling of the skeletal material and matching with the prenatal DNA would be able to achieve positive identification as the dental identification has narrowed down the search up to probable in this case study.

\section{Recommendation:}

When properly maintained and comprehensive dental records are not available, investigators should collect dental information as much as possible from the relatives. Furthermore, the checklist prepared by the author would be useful for forensic practitioners and police officers to maximize the AM data and for the process of AM data collection from the family members and the relatives of missing persons.

\section{Acknowledgement:}

1. Dr. K. Ratnasingham MO-Medico legal, JMO's office, ?Teaching Hospital Jaffna for providing AM information.

2. Mr. Nalin Hemanta Kumara, Forensic Photographer, ILMT, Colombo and the supportstaff of ILMT.

\section{References:}

1. Disaster victim identification guide, 2009, http:// www. interpol.int/ expertise/Forensics

1. 2.Pretty,I.A. and sweet D.(2001) a Look at Forensic Dentistry-part 1:The role of teeth in the Determination of Human identity. Br Dent J,190,359-66

2. 3.American Board of Forensic Odontology (1994) Body identification guidelines. J Am Dent Assiciation 125:1244-6.
3. Hilson, S. (1996), Dental Anthropology, $2^{\text {nd }}$ ed., Great Britain, University press: P225-228

4. Mukhopadhyay S, Mesiodens a clinical and radiographic study in children J Indian Soc Pedod Prev Dent. 2011 JanMar;29(1):34-8

5. Dalitz G.D.A. Radiographic study the rate at which human extraction wounds heal, Australian Dental Journal 1964

6. 7.MincerH.H,HarrisE.F,BerrymanH.E, (1993).The ABFO study of third molar development and its use as an estimation of chronological age.J For sci 38:379-90

7. 8.Cameriere, R.,et al., Accuracy of age estimation in children using radiograph of developing teeth .Forensic Sci.Int, 2008.176(2-3):p.1737.ndon:,1974:31-45

8. 9.Miles, A.E.W. (1963a) Dentition in the estimation of age. Journal of Dental Research, 1963; 42,255-263.

9. 10.Moorrees, C.F., Fanning, E.A. and Hunt, E.E. Jr. Age Variation Stages for Ten Permanent Teeth. Journal of Dental Research, 1963;42:1490-1502.

10. 11.Saunder, $S$ et al,Accuracy tests of tooth formation Age estimation for human skeletal remains, Am J Phys Anthropol,1993:92:133-188.

\section{Contribution of authors}

Performing the autopsy-NASPW, SR

Opinion- AS, NASPW, SR

Writing the manuscript -SR

Revising the manuscript- SR, NASPW 